\title{
AVALIAÇÃO NO COMPONENTE CURRICULAR CIÊNCIAS DA NATUREZA: UMA INVESTIGAÇÃO ENTRE PROFESSORES DO ENSINO FUNDAMENTAL DA REGIÃO DO ALTO VALE DO ITAJAÍ, SC
}

\author{
EVALUATION IN THE NATURAL SCIENCES CURRICULAR COMPONENT: AN \\ INVESTIGATION BETWEEN FUNDAMENTAL TEACHERS IN THE REGION OF ALTO \\ VALE DO ITAJAÍ, SC
}

Marcelo D'Aquino Rosa ${ }^{12}$

Recebido: fevereiro/2020 Aprovado: dezembro/2020

\begin{abstract}
Resumo: O artigo aborda a temática da avaliação em uma formação continuada, sendo participantes do projeto alguns professores de Ciências do Ensino Fundamental da região do Alto Vale do Itajaí, Santa Catarina. Partindo-se do problema referente à questão da avaliação nos processos de ensino e aprendizagem em aulas de Ciências da Natureza, o presente relato teve como objetivo geral identificar quais as concepções sobre avaliação entre os docentes que participaram da formação conduzida pelo autor. Ao longo do percurso formativo, os professores evidenciaram inicialmente concepções de avaliação voltadas para a noção de um instrumento avaliativo (prova, trabalho, relatório, seminário etc), enquanto noções mais amplas do processo foram manifestadas ao final do encontro. Tomando como base as perspectivas de avaliação de teóricos como Luckesi e Perrenoud, trabalhou-se também com o referencial metodológico da Análise de Conteúdo, analisando as respostas dos professores a uma tempestade de ideias referente à temática avaliação, em que os participantes deveriam expressar sua concepção sobre o termo em uma palavra. Por fim, acredita-se que algumas concepções iniciais foram quebradas ou modificadas, pois os professores manifestaram ideias diferentes após uma discussão conduzida pelo professor-formador, visando ampliar o conceito de avaliação.
\end{abstract}

Palavras-chave: Ciências da Natureza, Ensino Fundamental, Educação Básica, avaliação, formação de professores.

\begin{abstract}
This article addresses the theme of evaluation in a continuing education, the participants of this educational project were Science teachers of Elementary School Sciences from the Alto Vale do Itajaí region, Santa Catarina. Starting from the problem related to the question of evaluation in the teaching and learning processes in Natural Sciences classes, the present report aimed to identify which conceptions about evaluation were expressed by the teachers who participated in the training conducted by the author. Along the formative path, the teachers initially showed conceptions of evaluation focused on the notion of an evaluative instrument (test, work, report, seminar, etc.), while broader notions of the process were manifested at the end of the meeting. Based on the evaluation perspectives of theorists such as Luckesi and Perrenoud, we also worked with the methodological framework of Content Analysis, analyzing the teachers' responses to a brainstorm regarding the evaluation theme, where the participants should express his conception about the term in one word. Finally, it is believed that some initial conceptions were broken or modified, since the teachers expressed different ideas after a discussion conducted by the teachertrainer, aiming to expand the concept of evaluation.
\end{abstract}

http://orcid.org/0000-0002-0111-8540 - Doutor em Ensino de Ciências e Matemática - Programa de Pós-Graduação em Multiunidades em Ensino de Ciências e Matemática (PECIM) - Universidade Estadual de Campinas. Mestre em Educação Científica e Tecnológica - Programa de Pós-Graduação em Educação Científica e Tecnológica (PPGECT) - Universidade Federal de Santa Catarina. Bacharel e Licenciado em Ciências Biológicas - Universidade Federal de Santa Catarina. Professor da Educação Básica e do Magistério Superior.E-mail: marcelodaquino87@gmail.com.

${ }^{2} \mathrm{O}$ autor agradece a Leonam de Andrade Neves (http://lattes.cnpq.br/7805797404745052) pela revisão dos elementos textuais em língua inglesa no corpo do artigo. 
Keywords: Natural Sciences, Elementary School, Basic education, evaluation, teacher training.

\section{Introdução}

O termo "avaliação" pode representar diferentes concepções no campo educacional, uma característica conhecida como polissemia - a possibilidade de uma palavra possuir diferentes significados, todos com validade. Por esta razão, é importante que os professores da Educação Básica tenham discussões de cunho epistemológico em relação ao significado do termo, ao longo de diferentes espaços e momentos formativos.

É importante considerar, em termos da discussão desenvolvida, que a avaliação é tomada neste trabalho como um processo amplo, que

[...] incide sobre todos os demais elementos envolvidos na escolarização: transmissão do conhecimento, relações entre professores/as e alunos/as, interações no grupo, métodos que se praticam, disciplina, expectativas de alunos/as, professores/as, pais, valorização do ambiente educativo (Fernández Pérez, 1986). Estudar a avaliação é entrar na análise de toda a pedagogia que se pratica. (GIMENO-SACRISTÁN; PÉREZ-GOMEZ, 1998)

Assim, com o presente texto, não se pretende esgotar o assunto, mas sim trazer à luz algumas discussões referentes à temática, em especial o desenvolvimento dos processos de avaliação na Educação Básica, entre professores da área de Ciências da Natureza.

Teóricos como Cipriano Luckesi (1992) e Phillipe Perrenoud (1998) são dois dos autores que discutiram este assunto justamente pelo viés da amplitude do termo, apresentando diferentes concepções e modelos de avaliação. Para o primeiro, uma importante distinção é feita ao se diferenciar as noções de avaliação enquanto processo ou prova, duas concepções tomadas comumente como sinônimos, de acordo com o Quadro 1.

Quadro 1 - Concepções de "avaliação" e de "prova" e suas diferenças.

\begin{tabular}{c|c}
\hline Avaliação & Prova \\
\hline Processual & Pontual \\
\hline Contínua & Isolada \\
\hline Acompanhamento do desenvolvimento & Verificação parcial \\
\hline
\end{tabular}

Fonte: adaptado de Luckesi (1992).

Já para Perrenoud (1998), é importante o estabelecimento de um modelo de avaliação tido como ponto principal dos encontros ocorridos na formação desenvolvida em questão: o da avaliação formativa. Esta concepção de avaliação, de acordo com as ideias do autor, opõe-se a um modelo somativo por se preocupar com uma contribuição para melhoria da aprendizagem dos educandos, como pode ser observado no Quadro 2. 
Quadro 2 - Concepções de avaliação formativa e somativa e suas diferenças.

\begin{tabular}{c|c}
\hline Avaliação formativa & Avaliação somativa \\
\hline Qualitativa & Quantitativa \\
\hline Preocupação com aprendizagem & $\begin{array}{c}\text { Preocupação com medição/atribuição de um } \\
\text { índice }\end{array}$ \\
\hline $\begin{array}{c}\text { Sensível às concepções prévias e conhecimentos } \\
\text { anteriores dos estudantes, em especial quando } \\
\text { pensada em uma concepção diagnóstica }\end{array}$ & $\begin{array}{c}\text { Ênfase maior na devolutiva/feedback do } \\
\text { estudante ao instrumento avaliativo } \\
\text { (desempenho em termos de resultado) }\end{array}$ \\
\hline
\end{tabular}

Fonte: adaptado de Perrenoud (1998).

Considerando estes os princípios norteadores da proposta desenvolvida, o presente artigo trata-se de um relato de observação de um grupo de professores de Ciências da Natureza (Ensino Fundamental - anos iniciais e finais) em um curso de formação continuada sobre a temática "avaliação". Partindo-se do princípio que nem todas as formas de avaliação possuem as mesmas concepções e objetivos político-pedagógicos para os processos de ensino e aprendizagem, conforme referencial teórico abordado neste item, este trabalho objetivou identificar quais as concepções referentes à avaliação entre os docentes participantes da atividade, levantando hipóteses para as respostas obtidas.

A discussão é realizada com base na fundamentação teórica de autores voltados à abordagem sobre a temática e, para a interpretação dos resultados coletados no contexto deste estudo, a avaliação será considerada a partir de três categorias de análise, estabelecidas pelo autor, tomando a avaliação como um instrumento, um método ou um processo. No próximo item do texto será abordado o aspecto metodológico do estudo desenvolvido, com detalhamentos destes itens.

\section{Procedimentos Metodológicos}

O presente trabalho caracteriza-se como uma pesquisa de natureza qualitativa, um modelo em que a relevância do estudo está focada na interpretação dos dados, sem considerar como elemento central a importância à questão numérica dos resultados (MINAYO; DESLANDES; GOMES, 2011). Para a forma de análise dos dados, optou-se pela realização da Análise de Conteúdo (BARDIN, 2016), compreendida pelas etapas da leitura flutuante - visualização do material de estudo -, a exploração do material - os dados coletados - e, por último, análise dos resultados obtidos no contexto da pesquisa.

Como unidades de registro (UR), foram consideradas as respostas dadas pelos professores à dinâmica realizada no último momento do curso de formação, enquanto as unidades de contexto (UC) eram caracterizadas pela própria palavra "avaliação", representada nas concepções manifestadas espontaneamente pelos professores participantes. Para caracterizar as UR fornecidas pelos docentes, foi criada uma lista de categorias a priori (BARDIN, 2016), estabelecidas antes da análise das respostas, a saber: 1 - avaliação como instrumento; 2 avaliação como método; 3 - avaliação como processo. 
É importante delimitar, em termos do relato desenvolvido, que cada uma das categorias formuladas pelo autor, possui relação mais próxima com uma concepção referente à avaliação - formativa, somativa e/ou diagnóstica. Estas conexões serão estabelecidas ao longo do próximo item do texto, em que serão investigados alguns destes elementos em relação às respostas dos professores.

\section{Análise e Discussão dos Resultados}

A síntese das respostas fornecidas pelos professores participantes da investigação levou à construção do Quadro 3.

Quadro 3 - Respostas dos participantes à dinâmica realizada.

\begin{tabular}{|c|c|c|c|}
\hline & $\begin{array}{l}\text { Avaliação como } \\
\text { instrumento }\end{array}$ & Avaliação como método & Avaliação como processo \\
\hline $\begin{array}{l}\text { Exemplos em } \\
\text { respostas dos } \\
\text { professores } \\
\text { participantes }\end{array}$ & $\begin{array}{l}\text { "Medir" “Verificação” } \\
\text { “Conhecimento" “Prova” } \\
\text { “Conceito" “Medo" } \\
\text { “Devolver" “Resultado" }\end{array}$ & $\begin{array}{l}\text { "Diagnosticar" "Analisar" } \\
\text { "Relacionar" "Formar" } \\
\text { "Monitorar" }\end{array}$ & $\begin{array}{l}\text { "Reflexão" “Processo" } \\
\text { "Compreensão" } \\
\text { “Acompanhamento" } \\
\text { “Aprendizagem" } \\
\text { “Caminho" }\end{array}$ \\
\hline
\end{tabular}

Fonte: dados do autor.

De acordo com as menções no quadro anterior, temos diferentes concepções do termo "avaliação" muito presentes, de acordo com a fala dos professores e a exposição oral realizada pelo formador após este jogo de palavras. Há ideias a respeito do termo amarradas a um modelo de cunho mais somativo, enquanto outras remetem a uma avaliação em uma perspectiva formativa.

Quando se analisam as respostas encaixadas na categoria "avaliação como instrumento", por exemplo, a presença de verbos como "medir", "verificar" e substantivos como "conhecimento" fazem referência a uma concepção somativa de avaliação, na visão de Perrenoud (1998), pela forte presença de elementos que sirvam para mensurar o quanto o aluno sabe (ou não) a respeito de determinado conhecimento.

Há ainda, nesta categoria, a presença de palavras mais fortes e que denotam sentimentos da avaliação enquanto instrumento em uma concepção somativa, como "prova", "conceito", "medo", "devolver" e "resultado". Estes termos, em avaliação no grande grupo, foram mencionados por alguns docentes sempre se destacando também suas percepções e crenças individuais enquanto atores no processo educativo, seja atualmente como professores ou no passado, como estudantes.

No momento da conversa coletiva a respeito destas palavras com os professores, ficou evidente ainda, pela troca de ideias ocorrida, que esse instrumento seria quase sempre uma prova, um trabalho, um relatório etc, ou seja, algo que indicaria a presença de um índice, o estabelecimento de um ranqueamento, em que uns saberiam mais que outros, e que o grande indicativo deste saber seria a nota atribuída aos estudantes. Cabe colocar neste ponto que 
[...] para avaliar pode-se utilizar uma grande variedade de atividades, instrumentos e técnicas mas muitas vezes os instrumentos convertem-se em protagonistas, quando de fato são somente meios para alcançar diferentes atividades, isto sim, meios que podem facilitar a tarefa. (SANMARTí, 2009, p. 97)

Tratando-se as respostas dos professores adequadas à categoria da "avaliação como método", apresenta-se também neste momento uma terceira possibilidade para o termo: a avaliação diagnóstica. Nesta abordagem, de acordo com o Centro de Políticas Públicas e Avaliação da Educação (CAEd), da Universidade Federal de Juiz de Fora (UFJF), o objetivo seria

Fundamentalmente identificar as características de aprendizagem do aluno com a finalidade de escolher o tipo de trabalho mais adequado a tais características. Ou seja, a avaliação diagnóstica coloca em evidência os aspectos fortes e fracos de cada aluno, sendo capaz de precisar o ponto adequado de entrada em uma seqüência da aprendizagem, o que permite a partir daí determinar o modo de ensino mais adequado. Com esse tipo de avaliação previne-se a deteç̧ão tardia das dificuldades de aprendizagem dos alunos ao mesmo tempo em que se busca conhecer, principalmente, as aptidões, os interesses e as capacidades e competências enquanto pré-requisitos para futuras ações pedagógicas. (CAEd-UFJF, 2019, s/p).

Partindo da concepção de avaliação diagnóstica ora apresentada, através de palavras como "analisar", "diagnosticar", relacionar", "formar" e "monitorar", ficam evidentes a preocupação e o interesse do professor em medir aquilo que os estudantes sabem ou não, com fins de utilização pedagógica, para aprimoramento dos processos de ensino e aprendizagem. Esta preocupação foi expressa pelos docentes quando a dinâmica foi direcionada ao debate, sendo que muitos dos participantes colocaram a questão da avaliação diagnóstica enquanto ponto de partida para o início do ano letivo de trabalho. Ainda, estes expressaram conhecimento acerca da temática da avaliação diagnóstica, sendo este um tópico recorrente nas formações continuadas em suas redes e realidades locais.

Por último, a partir da definição de "avaliação como processo", construiu-se uma concepção de avaliação em uma perspectiva formativa (PERRENOUD, 1998), em que as respostas dos professores à dinâmica desenvolvida contemplaram palavras que remetem a um processo reflexivo, preocupado com questões pedagógicas e de aprendizagem de fato. Os participantes cujas respostas foram adequadas nesta categoria apresentaram uma concepção mais ampla da palavra avaliação, sendo essa não apenas um instrumento avaliativo como uma prova, na concepção de Luckesi (1992).

Como exemplos de palavras adequadas a esta última categoria, temos os termos "reflexão", "processo" e "compreensão", palavras expressas pelos professores no sentido de preocupação real com o processo de aprendizagem dos seus estudantes e acompanhamento longitudinal desta ação. Neste momento também foram utilizados termos como "acompanhamento", "aprendizagem" e "caminho" pelos participantes, o que novamente denota uma preocupação em torno da problemática da avaliação em uma concepção formativa.

Os docentes que reafirmaram este propósito manifestaram, através do debate conduzido pelo autor, que o desenvolvimento do aluno ao longo do ano letivo em suas disciplinas, os 
fazem, muitas vezes, considerar fatores como interesse, engajamento e participação aluno para o próximo ano escolar, mesmo quando o desempenho em termos de nota não é completamente satisfatório. Ficou evidente, então, uma preocupação maior destes docentes com a formação de seus estudantes enquanto sujeitos críticos e emancipados, caracterizando, assim, uma avaliação de caráter formativo em termos de práticas e concepções pedagógicas.

Pode-se considerar também, com base na discussão realizada neste último tipo de avaliação, que seria papel do professor a organização, de maneira proveitosa, do processo de avaliação da aprendizagem em seus estudantes (MORETTO, 2002). Assim, fica caracterizado o processo de avaliação em uma concepção formativa, voltado às questões pedagógicas de maneira mais profunda e menos focado em estabelecimento de uma nota ao aluno, por exemplo.

A análise dos dados presentes no contexto deste estudo ainda levou em conta um panorama, conforme mencionado anteriormente, de uma polissemia referente à palavra "avaliação", expressa de acordo com a Figura 1.

Figura 1 - Diversas concepções amarradas à palavra avaliação, representando a polissemia do termo.

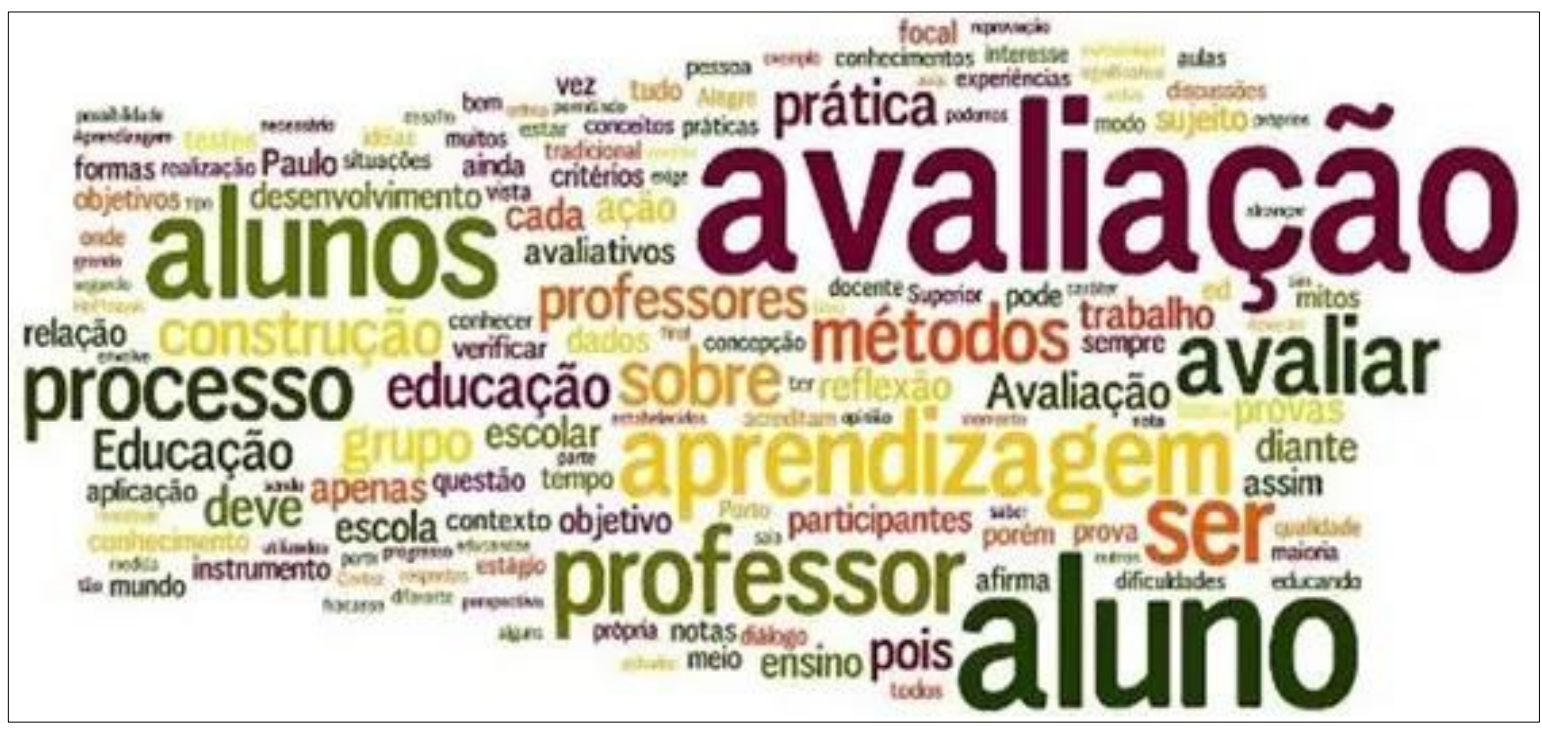

(Fonte: blog "Educação" - O Estadão, 2017).

Finalizando a análise dos dados ora apresentada, faz-se importante uma última ponderação: não se pretendeu, em momento ou tempo algum, estabelecer uma hierarquização entre as diferentes concepções de avaliação apresentadas aqui - ou mesmo entre as respostas fornecidas pelos professores participantes da atividade desenvolvida. O que se buscou, de fato, a partir desta investigação, foi uma discussão inicial a respeito da polissemia do termo avaliação e o quanto as concepções a ele amarradas podem divergir até certo ponto e, em outros casos, serem complementares, como é o caso das concepções diagnóstica e formativa.

\section{Considerações Finais}

Neste trabalho foram investigadas as concepções de avaliação entre professores de Ciências da Natureza do Ensino Fundamental da região do Alto Vale do Itajaí, Santa Catarina. 
Foram participantes cerca de 30 docentes dos anos iniciais e finais do Ensino Fundamental (1으9 o ano), sendo que a dinâmica final do momento formativo envolveu a escrita de uma única palavra referente ao termo em questão, para leitura e discussão posterior no grande grupo.

Os resultados aqui apresentados sinalizam que existem múltiplas concepções entre diferentes professores do contexto local, indicando a necessidade de se discutir mais e de maneira aprofundada o que se concebe como avaliação nas práticas educativas. Uma sugestão para isso é a inclusão da temática em encontros de professores nas redes, em especial àqueles momentos voltados à formação para prática e implementação da proposta apresentada na Base Nacional Comum Curricular (BRASIL, 2017).

Este documento, ao apresentar os objetos de conhecimentos (conteúdos) e habilidades (objetivos de aprendizagem), de certa forma, traz amarrado em si não apenas concepções de currículo, mas também de avaliação atreladas aos seus constituintes. Assim, a formação de professores para a utilização da BNCC junto às propostas curriculares locais necessita contemplar (mais) esta temática em suas propostas de trabalho.

Por último e reafirmando as reflexões do último parágrafo do item anterior, mais importante que definir quais concepções de avaliação seriam corretas ou incorretas, é necessário que se discutam as diferentes abordagens e formas presentes em nosso contexto educacional. Assim, o professor da Educação Básica pode escolher qual é a forma de avaliação que deseja desenvolver em suas aulas - e mesmo utilizar alguma forma intermediária entre todas estas propostas ou misturar as abordagens em seu trabalho, se assim o desejar.

\section{Referências}

BARDIN, L. Análise de conteúdo. São Paulo: Edições 70, 2016.

BRASIL. Base Nacional Comum Curricular (BNCC). Educação é a Base. Brasília, MEC/CONSED/UNDIME, 2017. Disponível em http://basenacionalcomum.mec.gov.br/. Acesso em 14/11/2019.

GIMENO-SACRISTÁN, J.; PÉREZ-GÓMEZ, A. Compreender e transformar o ensino. 4. ed. Porto Alegre: Artmed, 1998. 396 p.

Jornal "O Estadão". Blog "Educação". Disponível em https://educacao.estadao.com.br/blogs/vital-brazil/a-importancia-de-avaliar-o-processo-deensino-e-aprendizagem/. Acesso em 03/09/2019.

Centro de Políticas Públicas e Avaliação da Educação (CAEd) - Faculdade de Educação Universidade Federal de Juiz de Fora (UFJF). Portal da Avaliação - CAEd. Disponível em http://www.portalavaliacao.caedufjf.net/pagina-exemplo/tipos-de-avaliacao/avaliacaodiagnostica/. Acesso em 14/11/2019.

LUCKESI, C. C. Planejamento e avaliação na escola: articulação e necessária determinação ideológica. São Paulo: FDE, 1992. Série Idéias, n. 15, p. 115-125. Disponível em http://www.crmariocovas.sp.gov.br/pdf/ideias 15 p115-125 c.pdf. Acesso em 02/07/2019. 
MORETTO, V. P. Prova: um momento privilegiado de estudo, não um acerto de contas. 9. ed. Rio de Janeiro: Lamparina, 2010. 186 p.

MINAYO, M. C. S.; DESLANDES, S. F.; GOMES, R. Pesquisa social: teoria, método e criatividade. 30. ed. Petrópolis: Vozes, 2011. 108 p.

PERRENOUD, P. Avaliação - da excelência à regularização das aprendizagens: entre duas lógicas. Porto Alegre: Artes Médicas, 1999. 183 p.

SANMARTÍ, N. Avaliar para aprender. Porto Alegre: Artmed, 2009. 